\title{
Promoting health, preventing disease - making it happen
}

\section{Don Nutbeamª,b,c,d}

a Editor-in-Chief, Public Health Research \& Practice

b School of Public Health, University of Sydney, NSW, Australia

c Sax Institute, Sydney, NSW, Australia

d Corresponding author: don.nutbeam@sydney.edu.au

\section{Article history}

Publication date: December 2019 Citation: Nutbeam D. Promoting health, preventing disease - making it happen. Public Health Res Pract. 2019;29(4):e2941930.

https://doi.org/10.17061/phrp2941930
Countries around the world have developed strategies to address the challenge of achieving more in prevention. For example, at the time of writing the US has an established (if languishing) national strategy, England is undertaking public consultation on a draft strategy, and Australia is at an early stage in the development of a new strategy to prevent disease and improve health in their populations. ${ }^{1,2,3}$ Motivations for this are broadly common, partly social - recognising the need to support citizens to live longer, healthier lives - and partly economic, to reduce pressures on the health system and enable people to productively engage in the workforce. There is also an equity focus, with strategies that seek to improve everyone's health while also closing the health gap between different population groups.

\section{Success comes from sustained, comprehensive interventions}

The approaches taken almost always include a range of actions that reflect the complex causes of health and ill health. These include actions directed to individuals, focused on behaviours such as tobacco and alcohol use, food choices, and physical activity; actions directed at health services to ensure optimal provision and uptake of preventive services; and actions intended to create a more supportive environment for health - making healthy choices easier choices, and reducing exposure to harm. There is good reason for this multilevel approach. Most observable modern successes in public health, for example, mass immunisation and screening programs, tobacco control, and controlling the HIV epidemic, have all required combinations of public education, legislation and regulation, community engagement, and health services reorientation.

Conversely, we have very little evidence to suggest that individual actions such as public education campaigns can produce sustained public health benefits in isolation from other measures (regulation, environmental controls, community engagement). What matters is the synergy that comes from a multilevel and sustained set of interventions that reinforce the impact of any single action. Effective implementation has come through national and local government working in partnership with civil society groups and health services that are in more direct contact with individuals and communities. The best example of this in contemporary public health can be seen in those 
countries, such as Australia, that have been successful in achieving substantial and sustained reductions in tobacco use. No-one can suggest that this has been achieved through public education alone - it was the combination of public education with fiscal measures, environmental restrictions and access limitation that achieved the positive outcomes.

\section{Good strategy doesn't always lead to successful implementation}

So far, so good. We know what works, and have great case studies to point to. Sadly, examples of the conversion of strategy into sustained practical action are hard to find. The reasons for this are many and varied, including a poorly developed public health infrastructure - both people and systems; a lack of coordination across a disparate landscape - reinforced by large numbers of single-issue organisations and initiatives; and the reluctance of governments to use public policy to address the social and commercial determinants of health. This is often compounded by a lack of certainty about the effectiveness of specific interventions with disparate populations.

Developing a sound prevention strategy requires a sophisticated understanding of the complex underlying and immediate determinants of health - from social and economic environments to a person's individual behaviours. Effective implementation of a strategy requires easy access to the best available and most useable evidence on what works. Implementation also requires political buy-in, not only to short-term and visible interventions, but also to more complex, wholeof-government policies that meaningfully address the underlying social, economic and commercial determinants of health. To sustain implementation of a prevention strategy, we need a public health system and workforce that can provide leadership and coordination; and has the capacity to provide monitoring, evaluation and accountability. Getting these essential ingredients in place has often proved to be elusive. Bold national statements of intent are inclined to quickly regress to narrowly focused and short-term 'initiatives' that have political appeal but are of little proven benefit in isolation from more comprehensive and sustained programs. Governments are increasingly shy of regulating the commercial activities of big global enterprises such as those engaged in promoting unhealthy consumption of food, alcohol and sugar-sweetened beverages. ${ }^{4}$

\section{We need to learn from experience and be vigilant
about implementation}

The US has had an impressive, comprehensive national strategy that provides clear objectives and excellent technical guidance since 2011. ${ }^{1}$ This strategy clearly provided a mandate and inspiration for a broad range of government agencies and civil society organisations. But the US's highly devolved system of government and changes in its federal government, with a proudly unsympathetic President, mean that the chances of sustained implementation as originally intended in the Obama era are decidedly weak. The English consultation document on its prevention strategy focuses on "a new wave of intelligent public health". ${ }^{2}$ It highlights the potential of embedding genomics in routine health care and the promise of a "predictive prevention" work program to be led by Public Health England. The focus on prevention and the development of a coherent national strategy for England has much that is positive in it. Disappointingly, the document both directly and more insidiously (through a consistent focus on "the choices we make") steps away from what we have learnt about the social and commercial determinants of health over the past 50 years and offers a brave new world of public health "which is more proactive, predictive and personalised". The consultation is now closed. Hopefully, the feedback will result in a little more caution about the promise of prevention focused on unproven technology. Hopefully, it will urge a little more balance in recognising the importance of actions designed to mitigate the adverse impact of social and commercial determinants of health. We should all watch with interest.

In Australia, there is everything to play for. There is an excellent track record of success in public health interventions ${ }^{5}$; examples of positive leadership by governments, especially in tobacco control, gun control and road traffic injury prevention; examples of outstanding community engagement, especially in tackling HIV; and a broad-based, if somewhat disconnected, public health infrastructure drawing upon government agencies and civil society organisations. Many of the foundations for a comprehensive prevention strategy and its successful implementation are in place. What is now needed is a strategy that builds on success, offers a positive vision for the health and wellbeing of all citizens, and makes explicit how the strategy will be implemented and sustained. This will require political leadership, resource investment, and practical mechanisms to support and better coordinate government and civil society actions, backed by a system for monitoring and accountability. Again, we should all watch with interest. 
This edition of Public Health Research \& Practice is one of our non-themed editions and contains a rich cross-section of studies that illustrate the depth and breadth of intelligence available to those planning national prevention strategies. For example, the paper by Ooi et al. highlights the need to give attention to creating a more supportive environment for health in community sports venues by reducing promotion of fast food and sweetened drinks in these settings, and related dependency on sponsorship by companies marketing these products. ${ }^{6}$ Two papers, one by Crooks et al. ${ }^{7}$ and the other by Sherriff et al. ${ }^{8}$, highlight the importance of meaningful community engagement and control in all aspects of Aboriginal and Torres Strait Islander health data collection and intervention development. In considering how to optimise opportunities for primary and secondary prevention in the healthcare system, the paper by Faruqi et al. highlights the potential effectiveness of innovative primary care interventions to improve outcomes for people with type 2 diabetes, but identifies the challenge to get these adopted systematically in primary care in Australia ${ }^{9}$; and the paper by BrowneYung et al. highlights the importance of considering the social and economic circumstances of patients in a clinical setting, and the potential impact that this has on proposed care..$^{10}$ These, and the other papers in our current issue, add to the rich diversity of public health research available to policy makers to inform strategy development and support successful implementation.

\section{Acknowledgements}

DN is Professor of Public Health at the University of Sydney and Principal Senior Adviser at the Sax Institute. The views expressed in this article are his own.

\section{Peer review and provenance}

Internally reviewed, invited.

\section{Competing interests}

None declared.

\section{Author contributions}

DN is the sole author.

\section{References}

1. National Prevention Council. The national prevention strategy: America's plan for better health and wellness. Rockville, MD: Office of the Surgeon General; 2011 [cited 2019 Dec 19]. Available from: www.hhs.gov/sites/default/ files/disease-prevention-wellness-report.pdf

2. Department of Health and Social Care. Advancing our health: prevention in the 2020 s - consultation document. London: DHSC; 2019 [cited 2019 Dec 19]. Available from: www.gov.uk/government/consultations/advancingour-health-prevention-in-the-2020s/advancing-our-healthprevention-in-the-2020s-consultation-document

3. Australian Government Department of Health. National preventive health strategy. Canberra: Commonwealth of Australia; 2019 [cited 2019 Dec 19]. Available from: www1.health.gov.au/internet/main/publishing.nsf/Content/ national-preventive-health-strategy

4. Freeman B, Sindall C. Countering the commercial determinants of health: strategic challenges for public health. Public Health Res Pract. 2019;29(3):e2931917.

5. Public Health Association of Australia. Top 10 public health successes over the past 20 years. PHAA Monograph Series No. 2. Canberra: PHAA; 2018 [cited 2019 Dec 19]. Available from: www.phaa.net.au/documents/item/3241

6. Ooi JY, Wiggers JH, Kingsland M, Lecathelinais C, Tindall J, McFadyen T, Rowland BC, Sherker S, Murphy A, Heaton R, Wolfenden L. Exposure to fast food and sweetened drink marketing at community sports clubs in Australia. Public Health Res Pract. 2019;29(4):e2941929.

7. Crooks K, Carlson S, Dalton C. Defining, controlling and analysing Indigenous data: commitment to historical consistency or commitment to Australian Aboriginal and Torres Strait Islander peoples? Public Health Res Pract. 2019;29(4):e2941926.

8. Sherriff SL, Baur LA, Lambert MG, Dickson ML, Eades SJ, Muthayya S. Aboriginal childhood overweight and obesity: the need for Aboriginal designed and led initiatives. Public Health Res Pract. 2019;29(4):e2941925.

9. Faruqi N, Thomas L, Parker S, Harris-Roxas B, Taggart J, Spooner C, Wong V, Harris MF. Primary health care provider-focused interventions for improving outcomes for people with type 2 diabetes: a rapid review. Public Health Res Pract. 2019;29(4):e29121903.

10. Browne-Yung K, Freeman T, Battersby M, McEvoy DR, Baum F. Developing a screening tool to recognise social determinants of health in Australian clinical settings. Public Health Res Pract. 2019;29(4):e28341813.

\section{Copyright: (c) ()}

(C) 2019 Nutbeam. This article is licensed under the Creative Commons Attribution-NonCommercial-ShareAlike 4.0 International Licence, which allows others to redistribute, adapt and share this work non-commercially provided they attribute the work and any adapted version of it is distributed under the same Creative Commons licence terms. See: www.creativecommons.org/licenses/by-nc-sa/4.0/ 